\title{
Study of Adenoid Hypertrophy in HIV Infected Adult Individuals and its Impact on Otitis Media with Effusion
}

\author{
Saxena $\mathrm{A}^{* 1}$ and Saxena $\mathrm{S}^{2}$ \\ ${ }^{1}$ Department of Otorhinolaryngology, UPRIMS \& R, Senior Resident, Saifai, Etawah, UP, India \\ ${ }^{2}$ Department of Otorhinolaryngology, UPRIMS \& R, Medical Officer, Saifai, Etawah, UP, India
}

*Corresponding author: Saxena A, Department of Otorhinolaryngology, UPRIMS \& R, Senior Resident, Saifai, Etawah, Room No. 204, SR Hostel, DTH, UP, India, Tel: +91-9532306179, Email: arpitsaxenaexam@ gmail.com

Citation: Saxena A, Saxena S (2016) Study of Adenoid Hypertrophy in HIV Infected Adult Individuals and its Impact on Otitis Media with Effusion. J Aids Hiv Infec 2(1): 104. doi: 10.15744/2454-499X.2.104

Received Date: June 18, 2016 Accepted Date: August 29, 2016 Published Date: August 31, 2016

\begin{abstract}
Aim: To study the status of adenoids in Human Immune Deficiency Syndrome (HIV) infected individuals and its impact on otitis media with effusion.

Introduction: Adenoid is the condensation of lymphoid tissue at the posterosuperior wall of nasopharynx. Adenoids are part of waldeyer's ring. It is considered to have a crucial role in immunological memory of child. There are reported and documented evidences of adenoid hypertrophy in HIV infected individuals but there lack a large study of such cases. The idea of present study is to observe the status of adenoids in HIV infected individuals and its association with otitis media with effusion.
\end{abstract}

Materials and Methods: The study was conducted in department of otolaryngology of a tertiary care hospital. Patients were selected randomly from the register of ART centre of hospital that was undergoing treatment. 100 patients were selected who gave consent to include in study. A thorough otolaryngology examination was carried out which also included anterior rhinoscopy. All patients were then subjected to diagnostic nasal endoscopy. Adenoid status was recorded and X-ray neck soft tissue lateral view was done to confirm adenoid hypertrophy. In clinically suspected case of otitis media with effusion, tympanometry was done to confirm findings.

Results: The mean age of patients was 37.6 years. Most of the patients (61\%) were in age group of 31-45 years. Most of the patients (47\%) have third degree of adenoid hypertrophy. $42 \%$ patients have insignificant (I and II degree) adenoid hypertrophy and $58 \%$ had significant (III and IV degree). All the patients of III and IV degree adenoids were found to have otitis media with effusion on tympanometry.

Conclusion: Adenoid hypertrophy is uncommon among adult individuals. It is significantly present in HIV infected adult individuals and should be ruled out as cause of nasal complaints. Adenoid hypertrophy and otitis media with effusion are positively correlated.

Keywords: Human Immune Deficiency virus (HIV); Acquired Immune Deficiency Syndrome (AIDS); Adenoid Hypertrophy; Otitis Media with Effusion (OME)

\section{Introduction}

Adenoid is the condensation of lymphoid tissue at the posterosuperior wall of nasopharynx. Adenoids are part of waldeyer's ring. It is considered to have a crucial role in immunological memory of child [1]. Adenoids are usually present in children between age 6-10 years and usually regresses by 16 years [2].

Adenoids are usually not seen in adults and if seen are misdiagnosed and maltreated [3]. Adenoid hypertrophy (AH) in adults may be due to immunocompromised status such as organ transplant recipient, lymphoma and Acquired Immune Deficiency Syndrome (AIDS). Enlarged adenoids can achieve the size of a ping-pong ball and completely block the nasal passage. Further blockade may lead to recurrent sinusitis, rhinitis and acute otitis media.

There are reported and documented evidences of $\mathrm{AH}$ in Human Immune Deficiency Syndrome (HIV) infected individuals but there is lack of a large study of in such cases. The rationale of this study is to evaluate an uncommon entity of AH in adults. Moreover, HIV patients are known to be suffering from OME frequently. Therefore, this study was done to know the incidence of $\mathrm{AH}$ and its impact on OME. Present study was done on patients suffering with HIV and who were under antiretroviral therapy (ART). 


\section{Materials and Method}

The study was conducted in the department of otolaryngology of a tertiary care hospital from October 2015 to March 2016. Patients were selected randomly from the register of ART centre of hospital that was undergoing treatment. Patients were communicated telephonically and were invited for study enrolment. 100 patients were selected who gave consent to include in study. The inclusion and exclusion criteria are as follows-

\section{Inclusion criteria}

1. Patients with regular follow up at ART centre

2. Age $>16$ years of either sex

3. Patient undergoing ART

4. Willing for further investigations as advised

5. Patients giving consent

\section{Exclusion criteria}

1. Patients having acute upper respiratory tract infection

2. Pregnant and breast feeding patients

3. Patients with irregular follow up at ART centre

4. Patients not giving consent

100 random patients were communicated by their registered telephone number in directory of ART centre. After obtaining inclusion and exclusion criteria patients were called in otolaryngology Outdoor Patient Department (OPD). Their detailed history of HIV infection duration and nasal complains if any were noted. A thorough otolaryngology examination was carried out which also included anterior rhinoscopy and otoscopic examination. All patients were then subjected to diagnostic nasal endoscopy.

Nasal endoscopy was performed after nasal decongestion with $4 \%$ lignocaine and $0.5 \%$ xylometazoline solution packs. Whole procedure was done with zero degree endoscope and Stammberger technique being used [4]. In order to decide the degree of adenoid hypertrophy, system used by Cassano, et al. was used (Table 1) [5].

Patients having adenoid hypertrophy third degree and above were subjected to X- ray to confirm finding. X-ray nasopharynx lateral view in erect position with the neck extended and mouth opened to visualize the shadow of adenoid. All the patients clinically suspected for OME were subjected to tympanometry to confirm finding. All the results were documented and statically analyzed using SPSS software 14.0.

\begin{tabular}{|c|c|c|}
\hline S.NO. & DEGREE & SPACE OCCUPIED BY ADENOIDS \\
\hline $\mathbf{1}$ & I & Upper segment in the rhinopharyngeal cavity $(<25 \%)$ \\
\hline $\mathbf{2}$ & II & Upper half $(<50 \%)$ of the rhinopharyngeal cavity \\
\hline $\mathbf{3}$ & III & $\begin{array}{c}\text { Extended over the rhinopharynx }(<75 \%) \text { with obstruction of choanal openings and partial } \\
\text { closure of tube ostium }\end{array}$ \\
\hline $\mathbf{4}$ & IV & Both the tube ostium and the lower choanal border could not be observed, (75-100\%) \\
\hline
\end{tabular}

\section{Results}

The study was carried for 06 months in the department of otolaryngology. 100 patients were included in study. The range of age varied from 17-56 years. The mean age of patients was 37.6 years. Most of the patients (61\%) were in age group of 31-45 years. The age distribution is described in Table 2.

\begin{tabular}{|c|c|c|}
\hline S.NO. & AGE (YEARS) & NUMBER OF PATIENTS \\
\hline $\mathbf{1}$ & $17-30$ & 11 \\
\hline $\mathbf{2}$ & $31-45$ & 61 \\
\hline $\mathbf{3}$ & $>46$ & 28 \\
\hline \multicolumn{3}{|c|}{ Table 2: Age Distribution } \\
\hline
\end{tabular}

Out of 100 patients 39 were female and 61 were male. Sex distribution of patients is depicted in Table 3. Duration of HIV infection is tabulated in Table 4. Most of the HIV infected patients (61\%) were known to be infected for 3-6 years. The duration of infection is accounted from the day patients were confirmed HIV positive by standard laboratory tests.

\begin{tabular}{|c|c|c|}
\hline S.NO. & SEX & NUMBER OF PATIENTS \\
\hline $\mathbf{1}$ & Male & 61 \\
\hline $\mathbf{2}$ & Female & 39 \\
\hline
\end{tabular}

Table 3: Sex Disribution 


\begin{tabular}{|c|c|c|}
\hline S.NO. & $\begin{array}{c}\text { DURATION OF } \\
\text { INFECTION (YEARS) }\end{array}$ & NUMBER OF PATIENTS \\
\hline $\mathbf{1}$ & $<3$ & 14 \\
\hline $\mathbf{2}$ & $3-6$ & 61 \\
\hline $\mathbf{3}$ & $6-9$ & 25 \\
\hline
\end{tabular}

Table 4: Duration of HIV Infection

Diagnostic nasal endoscopy was performed in each patient. Most of the patients (47\%) have third degree of adenoid hypertrophy. $42 \%$ patients have insignificant (I and II degree) adenoid hypertrophy and 58\% had significant (III and IV degree) AH. Result of adenoid hypertrophy is tabulated in Table 5.

\begin{tabular}{|c|c|c|}
\hline S.NO. & $\begin{array}{c}\text { DEGREE OF ADENOID } \\
\text { OBSTRUCTION }\end{array}$ & NUMBER OF PATIENTS \\
\hline $\mathbf{1}$ & I & 11 \\
\hline $\mathbf{2}$ & II & 31 \\
\hline $\mathbf{3}$ & III & 47 \\
\hline $\mathbf{4}$ & IV & 11 \\
\hline
\end{tabular}

Table 5: Adenoid Hypertrophy Distribution in Patients

$67 \%$ patients were clinically suspected for OME. All these were subjected to tympanometry and $63 \%$ patients were found to have type 'B' graph suggestive of fluid in middle ear. All the patients of III and IV degree were found to have type 'B' graph and 5\% patients of II degree were found to have type 'B' graph in tympanometry (Table 6).

\begin{tabular}{|c|c|c|c|c|}
\hline S.NO. & $\begin{array}{c}\text { DEGREE OF } \\
\text { ADENOID } \\
\text { OBSTRUCTION }\end{array}$ & $\begin{array}{c}\text { NUMBER OF } \\
\text { PATIENTS }\end{array}$ & $\begin{array}{c}\text { NUMBER OF PATIENTS } \\
\text { CLINICALLY } \\
\text { SUSPECTED FOR OME }\end{array}$ & $\begin{array}{c}\text { NUMBER OF PATIENTS } \\
\text { WITH OME ON } \\
\text { TYMANOMETRY }\end{array}$ \\
\hline $\mathbf{1}$ & I & 11 & 00 & 00 \\
\hline $\mathbf{2}$ & II & 31 & 05 & 00 \\
\hline $\mathbf{3}$ & III & 47 & 11 & 47 \\
\hline $\mathbf{4}$ & IV & 11 & \multicolumn{2}{|c|}{ Table 6: Clinically suspected for OME } \\
\hline
\end{tabular}

There was positive correlationship between AH and OME in HIV infected individuals. It was also observed that most of the subjects with AH were the individuals who were infected for period of 3-6 years. The duration of ART treatment was not accounted in this study.

\section{Discussion}

Santorini described nasopharyngeal aggregates or "Luschka tonsils" in year 172 [6]. Wilhelm accounted for term nasopharyngeal vegetations as adenoid in 1870. The adenoid forms part in waldeyer's ring that helps in preventing bacteria, virus and toxins entering the body. The adenoids are composed of B lymphocytes which form various antibodies against bacteria and viruses. Adenoids are usually hypertrophic in children and regresses by the age of 16 years.

Adenoids are like tonsils and can become hypertrophic in acute and chronic infections. Due to chronic infection and inflammation, adenoid gradually gets hypertrophic. Presence of AH in nasopharynx leads to nasal obstruction. Adenoids have shown to play crucial role in immunological memory of younger children. Adenoidectomy may sound immunologically undesirable at young age but there has been no alteration in Ig E level after adenoidectomy [7,8]. An adenoid physiologically gets hypertrophy in children of 6-10 years and regresses by 16 years [2].

However, adenoid usually regresses by 16 years of age but it is also seen in adult population [9,10]. Due to low incidence of adenoid enlargement in adults and access to adenoids is difficult by direct examination, many cases of adenoid hypertrophy are misdiagnosed and maltreated [3]. However, the adenoid hypertrophy causes are exactly unknown, but some reasons have been proposed. One of the causes is persistence of childhood adenoids associated with chronic inflammation [3]. Infection and irritant may also lead to proliferation of adenoids [11]. Finkestein, et al. shows that $30 \%$ heavy smokers had adenoid hypertrophy but in study of Barcin C, et al. smoking was not associated as a significant etiology $[12,13]$.

Hamdan, et al. documented prevalence of AH in patient with nasal obstruction to be $63.6 \%$ whereas Rout MR, et al. reported $21 \%$ prevalence [6]. In present study the incidence of significant AH were 58\%. The possible causes of adenoid hypertrophy in adults are allergic rhinitis, Non-Hodgkin's lymphoma, malignant tumors and AIDS [6,14].

Manifestation of AIDS in head and neck are among the most common complication of this disease. Some manifestation present as initial signs of HIV and others were present with full blown AIDS. AH can be one of the presentations. OME is one of the associated presentations [15]. 
In our study we found a significant number of patients of AIDS to have adenoid hypertrophy irrespective of their nasal complaints. All the subjects were under retroviral therapy. In present study most of the patients were 31-45 years of age. The two possible reasons for this being that this group is more sexually active and it also corresponds to the national databases [16]. Most of individuals were male which also corresponded to national database [16]. 58\% patients were having significant AH (third and fourth degree). $69 \%$ patients were having complaints of nasal obstruction. On endoscopy $43 \%$ patients were found to have deviated nasal septum (DNS). Due to presence of AH as well as DNS, it was not sure whether nasal obstruction is attributable to DNS or adenoid hypertrophy. It was also observed that most patients having AH were belonging to the group of 3-6 years of HIV infected individuals. This can be explained on two bases. Firstly, that most individuals in this study belonged to 3-6 years and secondly the duration of such prolonged HIV infection leading such possibility. All the patients with significant AH were found to have OME on objective assessment by tympanometry as well as 5\% patients of II degree also. This embarks the significance of AH leading to otological symptoms in adult population.

Our study uncovers the presentation of significant AH in HIV infected individuals who were selected randomly. Moreover, a positive correlationship of AH with OME was also observed. This shows that correcting AH by conservative or surgical means will lead to relieve in nasal symptoms as well as otological symptoms. Further research should seek into histopathological examination and study of CD4 counts association with $\mathrm{AH}$.

\section{Conclusion}

$\mathrm{AH}$ is uncommon among adult individuals. $\mathrm{AH}$ in adults should be thoroughly investigated keeping AIDS as important differential diagnosis. AH is significantly present in HIV infected adult individuals and should be ruled out as cause of nasal complaints. AH and OME are having significant positive correlationship in HIV infected individuals.

\section{References}

1. Wysocka J, Hassmann E, Lipska A, Musiatowicz M (2003) Naïve and memory T cells in hypertrophied adenoids in children according to age. Int J Pediatr Otorhinolaryngol 67: 237-41.

2. Yildrim N, Sahan M, Karsliglu Y (2008) Adenoid hypertrophy in adults: clinical and morphological characteristics. J Int Med Res 36: 157-62.

3. Kamel RH, Ishak EA (1990) Enlarged adenoid and adenoidectomy in adults: endoscopic approach and histopathological study. J Laryngol Otol 104: 965-7.

4. Scott-Brown's (2008) Scott-Brown's Otorhinolaryngology, Head and Neck surgery (7 $7^{\text {th }}$ edn), CRC Press Taylor and Francis group, London 2: $1347-48$.

5. Cassano P, Gelardi M, Cassano M, Fiorella ML, Fiorella R (2003) Adenoid tissue rhinopharyngeal obstruction grading based on fiberendoscopic findings: a novel approach to therapeutic management. Int J Pediatr Otorhinolaryngologol 67: 1303-9.

6. Rout MR, Mohanty D, Vijalaxmi Y, Bobba K, Metta C, et al. (2013) Adenoid Hypertrophy in Adults: A case Series. Indian J Otolaryngol Head Neck Surg 65: 269-74.

7. Brandtezaeg P (2003) Immunology of the tonsils and adenoids: everything the ENT surgeon needs to know. Int J Pediatr Otorhinolaryngol 67: S69-76.

8. Modrzynski M, Zawisza E, Rapiejko P (2003) Serum immunoglobulin E levels in relation to Waldeyer's ring surgery. Przegl Lek 60: $325-8$.

9. Yuce I, Somdas M, Ketenci I, Caqli S, Unlu Y (2007) Adenoidal vegetation in adults: an evaluation of 100 cases. Kulak Burun Boqaz Ihtis Derg 17: 130-2.

10. Minnigerode B, Blass K (1974) Persistent adenoid hypertrophy. HNO 22: 347-9.

11. Frenkiel S, Black MJ, Small P (1980) Persistent adenoid presenting as a nasopharyngeal mass. J Otolaryngol 9: 357-60.

12. Finkelstein Y, Malik Z, Kopolovic J, Bernheim J, Djaldetti M, et al. (1997) Characterization of smoking-induced nasopharyngeal lymphoid hyperplasia. Laryngoscope 107: 1635-42.

13. Barcin C, Tapan S, Kursakloglu H, İyisoy A, Köse S, et al. (2005) Tu“rkiye!desagథlikli genc, eris, kinlerde koroner risk fakto“rlerinin incelenmesi: Kesitsel bir analiz. Türk Kardiyoloji Dern Ars 33: 96-103.

14. Hamdan AL, Sabra O, Hadi U (2008) Prevalence of adenoid hypertrophy in adult with nasal obstruction. J Otolaryngol Head Neck Surg $37: 469-73$.

15. Moazzez AH, Alvi A (1998) Head and neck manifestations of AIDS in adults. Am Fam Physician 57: 1813-22.

16. National AIDS Control Organisation (2015) India HIV Estimates. NACO Technical Report Government of India, India.

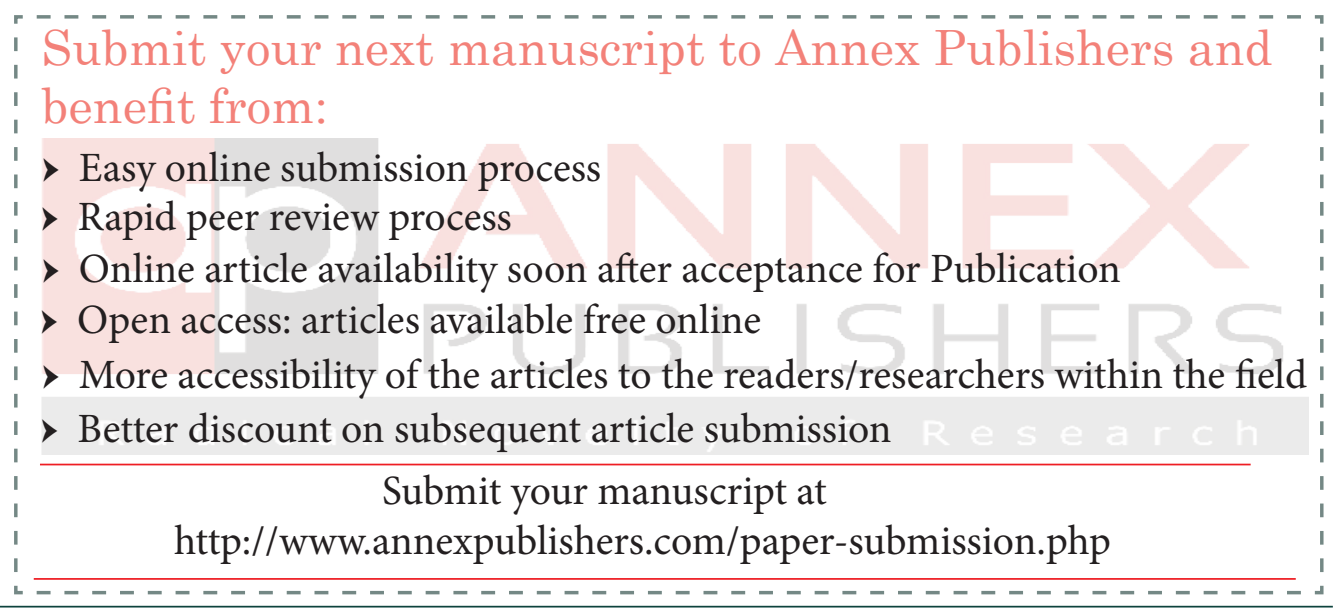

